\title{
Does Patenting Help High-Tech Start-Ups?
}

\author{
Christian Helmers and Mark Rogers \\ Wolfson College and Harris Manchester College, \\ University of Oxford
}

\section{Intellectual Property Research Institute of Australia Working Paper No. 06/09 \\ ISSN 1447-2317}

\section{May 2009}

Intellectual Property Research Institute of Australia

The University of Melbourne

Alan Gilbert Building

Victoria 3010 Australia

Telephone: 61 (0) 383442153

Fax: 61 (0) 383442111

Email: info@ipria.org

www.ipria.org 


\title{
Does Patenting Help High-Tech Start-Ups?*
}

\author{
Christian Helmers \\ Wolfson College \\ University of Oxford
}

\author{
Mark Rogers \\ Harris Manchester College \\ University of Oxford
}

January 2009

\begin{abstract}
Using data on all high- and medium-tech start-ups in the UK in 2000, this paper looks at whether the decision to patent affects subsequent growth in total assets between 2001 and 2005. Identifying any patent effect relies on specific assumptions concerning the timing and nature of the patent decision. The low survival rate of firms, 40\% fail before 2005, means we control for sample selection. The findings suggest that patentees may have asset growth of between $6 \%$ to $17 \%$ per annum higher that non-patentees. There is some evidence that EPO patents are particularly beneficial to the smallest start-ups.
\end{abstract}

KEYWORDS: Patents, start-ups, growth

JEL Classification: L26, O34

${ }^{*}$ The authors acknowledge financial support from UK Intellectual Property Office (IPO), and comments received from seminar participants at the EPO (November, 2007), UK IPO (May and December 2008) and the 3rd Annual Conference of the EPIP Association (October 2008); Paul Jensen also made useful comments. Christine Greenhalgh has also been involved in constructing the data set and in many discussions. Authors' email addresses: Christian Helmers: christian.helmers@wolfson.ox.ac.uk; Mark Rogers: mark.rogers@hmc.ox.ac.uk. 


\section{Introduction}

The question in the title can be interpreted in various ways. Perhaps the most straightforward interpretation is 'do patents improve the growth, profitability or productivity of patenting small firms when compared to firms that do not patent?' The issue is one of private, firm-level performance and comparing patentees with non-patentees. The major difficulty in providing any information on this issue is one of data. First, one must have data on the patenting of smaller firms. Obtaining such data normally encounters a large sample selection problem: small data sets, surveys or case studies often just look at successful firms and also those keen to report the success of their patents. Second, one needs financial data on some performance measure, ideally after the patent was filed, published or granted. Third, given the absence of the counterfactual (i.e., what would a firm's performance have been, had it not patented?) a good test requires a comparison with a control group of non-patentees. This control group needs to contain similar small firms; in other words small firms that are engaged in invention and innovation but, for whatever reason, chose not to patent. Given the huge heterogeneity of small firms, and also in the innovation process, finding a control group is a difficult task. This is compounded by the fact that smaller firms report relatively little data on their activities.

The above reasons account for why there are very few research papers in this area. ${ }^{1}$ Nevertheless, policymakers are very interested in the issue of small firms and patenting (Gowers, 2006). The patent system aims to give inventors and small firms some protection in their entrepreneurial endeavors. We certainly hope, for example, that important new inventions can rely on some level of protection as they are developed into innovations and tested in the market place. This line of thinking implies that only a few patents lead to important and successful innovations, while many patents are of little value. The skewed distribution of patent values is well known (e.g. Schankerman and Pakes, 1986; Gambardella et al., 2008). Some of these patents are associated with smaller firms, hence the skewed patent value distribution is also reflected in the skewed distribution of performance of smaller firms. Studies on new firms show that around $50 \%$ fail before 5 years and that only a tiny proportion grow to be large firms (Mata and Portugal, 1994; Disney, Haskel and Heden, 2003). There is, therefore, a parallel between the patent value distribution and the new firm performance distribution. This can be referred to as the ' 1 in a 100' issue where we might expect only 1 in a 100 patents or small firms to be valuable or successful - although, clearly, we do not have

\footnotetext{
${ }^{1}$ An exception is Buddelmeyer et al. (forthcoming) which looks at survival and intellectual property for all Australian firms.
} 
any evidence on whether this ratio is appropriate. The ' 1 in a 100' issue raises another way of interpreting the question in the title. We could say that patents improve the performance of small firms if they ensure that ' 1 in a 100' achieve success (i.e., without the patent system not even this one firm would survive). This discussion brings to our attention another difficult issue when working with small firms: it is important to have large samples, and preferably population data, so as to track all outcomes. Failing to look at the entire population could easily lead to biased results depending on whether the ' 1 in a 100' firm is included or excluded. ${ }^{2}$

Faced with the various problems discussed above, this paper is based on a project that has collated IP data on all UK registered firms over the period 2000 to date. The data set also has complete data on all UK registered firms to construct control groups. Specifically, for the purposes of this paper we focus attention on medium- and high-tech industries as these are the ones most likely to face the choice to patent. Further, given the huge attrition rate of new firms, we know that comparing a ten year old small firm, with a two year old small firm, is ill advised. A ten year old firm has a much greater chance of survival. It has already made a success of its initial innovation(s), which is why firms are formed in the first place. The two year old firm is still attempting to make a success of its innovation(s). This means if we are interested in assessing the role of patents in the performance of small firms, it is best to compare firms of similar age.

In order to do this, we take all new firms incorporated in 2000 in the UK $(7,638)$ in medium- and high-tech industries and calculate their average annual growth rate between 2001 and 2005 (for the approximately 60\% of start-ups that survive). Our data allows us to identify the 303 start-ups that filed for a patent in 2000 or 2001. In addition, we account explicitly for the possibility that firms were set up with the purpose to capitalize on an invention made prior to the incorporation of the firm. This is done by matching the names of the firms' directors to patent names. We include any directors' patents in 1999, 2000 or 2001 . We then ask whether the performance of patentees is different from non-patentees.

The paper is structured as follows. The following section discusses the assumptions necessary to allow us to identify any impact of patenting on performance. As will

\footnotetext{
${ }^{2}$ Of course, the term 'biased' depends on what objective the research has. For example, Hicks and Hegde (2005) look only at small US firms with 15 or more patents in the 1996-2000 period that survived until 2002. Such papers are interested only in the highly innovative firms and investigating aspects of their behaviour, markets-for-technology in this case.
} 
become clear, even with complete population data there are a host of problems facing the analysis. Section 3 describes the data set and Section 4 provides some descriptive analysis. Section 5 discusses the results of our model. Section 6 contains a robustness test. The last section concludes.

\section{Identification}

As is clear from the introduction, the problem in assessing whether patents affect the performance of smaller firms is in identifying any patent effect. The ideal situation is to have two groups of firms with inventions and with plans to turn these into new innovations in the market. One group decides not to patent its inventions and the other does, with this decision ideally being made randomly! The question is then whether the performance of the patenting (treatment) group differs from the non-patenting (control) group. If we had data from a randomized experiment, we could simply compare the two distributions conditioning on possible systematic differences between patenting and non-patenting firms, which would influence their performance even in the hypothetical absence of any patents. ${ }^{3}$ This would be, in principle, sufficient to draw inference on the estimated coefficient of patenting on firm growth. In reality we cannot set up such a controlled experiment - firms choose whether to patent - and we are left with an identification problem well known in the 'treatment' literature.

To summarize, there are three main difficulties in point-identifying the effect of a firm's decision to patent on its eventual performance. First, firms are heterogeneous. If all firms had similar inventions and were identically endowed with regard to possible determinants of their patenting decision, all firms would behave identically in choosing whether to patent or not. But firms differ in many respects with regard to these determinants. To the extent that heterogeneity is observable through, for example, measures of firm size, the problem can be addressed as pointed out above. However, it is highly unlikely that conditioning on these observable factors wipes out entirely firm heterogeneity. Given the unobserved heterogeneity, the differences between the outcome distributions of patenting and non-patenting firms may confound the effect of patenting with unobserved differences in the population. Second, a firm's decision to patent and its performance are characterized by a simultaneous relationship: A firm's

\footnotetext{
${ }^{3}$ Controlling for such differences, we avoid confounding differences in the outcome variable across the two groups with a patent effect due to these systematic differences - this assumption is therefore commonly referred to as 'unconfoundedness' in the treatment literature (Rosenbaum and Rubin, 1983). Crucially, these variables have to be exogenous in the sense that they need to be unaffected by a firm's decision to patent in order to guarantee that the patent indicator is uncorrelated with omitted variables affecting growth.
} 
decision to patent may depend on its performance and vice versa. Third, as is wellknown, a large share of firms exits the market every year. Omitting firms that have failed from any performance analysis is likely to introduce selection bias in the estimation.

Figure 1: Time line

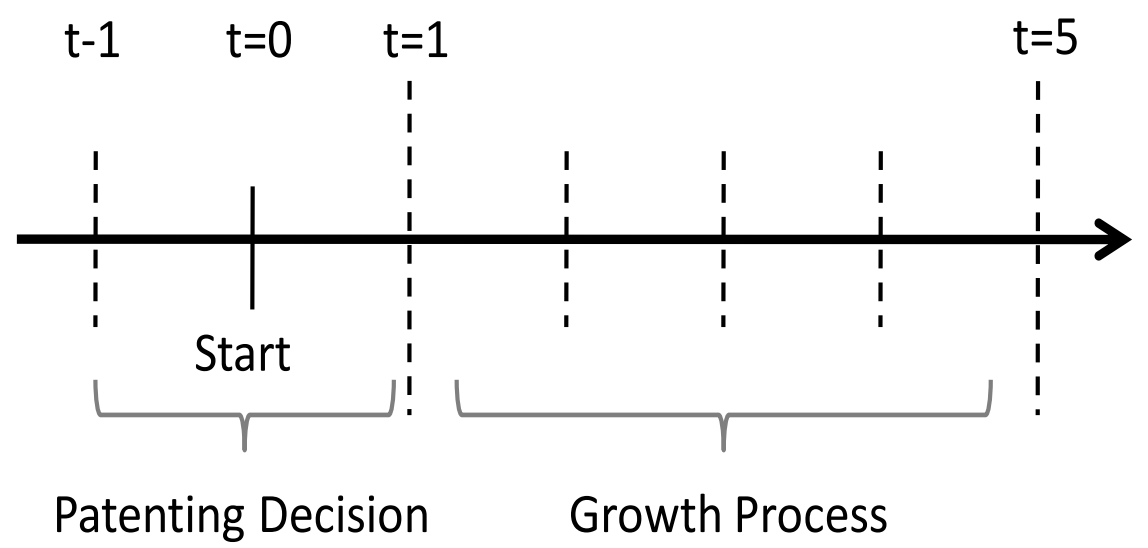

In order to address these three issues we adopt the following identification strategy. First, in order to minimize unobserved firm heterogeneity, we restrict our sample to a cohort of high- and medium-tech firms incorporated in 2000. We assume that a firm is incorporated with the objective to capitalize on an invention made before the date of incorporation. ${ }^{4}$ In high- and medium-tech sectors, this assumption appears credible. This assumption is not testable with our data, although we do estimate the model on a narrower sub-set of industries as a robustness check.

Second, we tackle the simultaneity issue by considering the assumptions surrounding the time at which a patent is applied for. Once the invention is made, the founder of the new company has the choice to apply for a patent. Hence, patents are applied for either (1) shortly before a company is incorporated by one of its eventual directors or (2) by the firm itself shortly after it has been incorporated. Importantly, the decision to patent the invention on which the company bases its commercial objec-

\footnotetext{
${ }^{4}$ Also note that while we attempt to reduce firm heterogeneity through sample homogeneity, one could also argue that firms in our sample are subject only to uncertainty not heterogeneity at the moment in which they decide to patent. According to Browning and Carro (2006), heterogeneity refers to a situation when firms know their individual type is characterized by a number of factors determining its actions. Hence, if firms hold identical beliefs about the patentability of their invention, there is no heterogeneity affecting the observed patenting decisions.
} 
tive, arises before a firm starts competing in the market as shown in Figure 1. This is an important timing assumption because it allows us to assume that the patenting decision is exogenous with regard to firm performance. A related issue is whether entrepreneurs, at the time of patenting, have good information on the expected value of their invention and only patent those inventions with high expected values. Some papers assume that the patent decision is made once the expected value of the related innovation is known (Arora et al., 2008). In the current context of analyzing start-up firms and their initial decisions to patent, this assumption of perfect foresight appears too strong. Entrepreneurs are by nature optimistic and expect their projects to be successful, yet there are large failure rates, something that is studied by the literature on rates of return, bank finance and venture capital (Astebro, 2003). Further, even if entrepreneurs do have some imperfect information on expected outcomes, it is not clear that all valuable inventions are patented. There is evidence that other strategies, such as secrecy and first mover advantage, may be used instead. From an econometric point of view, firms may hold private information regarding the value of their invention; we require only that this private information is uncorrelated with the patenting decision conditional on a vector observed firm characteristics entering the growth equation. ${ }^{5}$

Third, the issue of selection bias is addressed through a standard Heckman (1976, 1979) selection model. Our objective is to estimate the growth equation

$$
\triangle y_{i}^{*}=\beta_{x} X_{i}+\nu_{i}
$$

where $\triangle y_{i}^{*}$ denotes firm $i$ 's growth rate, $X_{i}$ are exogenous covariates including the patent variable. We assume that the unknown error $\nu_{i}$ is normally distributed. The problem with (1) is that $y_{i}^{*}$ is observed only if a firm does not exit during the period analyzed. If we denote a firm's decision to stay in the market or exit as $s_{i} \in(0,1)$, we observe $\triangle y_{i}^{*}$ if and only if $s_{i}=1$; we denote the observed growth rate as $\triangle y_{i}$. Therefore, we can rewrite (1) as

$$
\triangle y_{i}=\beta_{x} X_{i}+\nu_{i} \quad \text { iff } \quad s_{i}=1
$$

Selection bias arises if $\operatorname{Cov}\left(X_{i}, \nu_{i} \mid s_{i}=1\right) \neq 0$, i.e., if in the observed sample of surviving firms' covariates are no longer exogenous. To see this problem more clearly, we parameterize a firm's decision to stay in the market as

\footnotetext{
${ }^{5}$ This is again the standard unconfoundedness or 'selection on observables' assumption in the treatment literature.
} 


$$
s_{i}= \begin{cases}1 & \text { if } \beta_{z} Z_{i}+\varepsilon_{i} \geq 0 \\ 0 & \text { otherwise }\end{cases}
$$

where $Z_{i}$ denotes firm characteristics influencing a firm's decision to stay in the market. Importantly, to ensure identification of $\beta_{x}$ in (1), $Z_{i}$ must contain at least one variable excluded from $X_{i}{ }^{6}$ Using (3), we can rewrite (1) as

$$
E\left(\triangle y_{i} \mid X_{i}, s_{i}=1\right)=\beta_{x} X_{i}+E\left(\nu_{i} \mid X_{i}, s_{i}=1\right)=\beta_{x} X_{i}+E\left(\nu_{i} \mid \varepsilon_{i}\right)
$$

We therefore encounter selection bias if $\operatorname{Cov}\left(\nu_{i}, \varepsilon_{i}\right) \neq 0$, which is the case if there are unobservables affecting growth as well as firm survival. In addition, if the variables in the growth equation are correlated with the variables in the selection equation, provided that $\operatorname{Cov}\left(\nu_{i}, \varepsilon_{i}\right) \neq 0, X_{i}$ is no longer exogenous in (1). Heckman (1976) proposed a well-known solution based on the assumption that $\nu_{i}$ and $\varepsilon_{i}$ are jointly normally distributed. Then equation (3) can be used to estimate a correction term which is used as an additional regressor in (4) proxying $E\left(\nu_{i} \mid \varepsilon_{i}\right)$. If the model is correctly specified, the most efficient estimators are obtained from estimating equations (4) and (3) jointly by Full Information Maximum Likelihood (FIML). While this method has received an astonishing amount of attention in the literature, it is important to stress that using the Heckman approach, equation (4) is estimated including a selection correction term as $E(\triangle y \mid x, s=1)=x \beta+\sigma \rho \frac{\phi(\cdot)}{\Phi(\cdot)}$, where $s=1$ denotes survivor firms, $\frac{\phi(\cdot)}{\Phi(\cdot)}$ the inverse Mills Ratio estimated based on (3), and $\rho$ the correlation between the errors of the selection and growth equations and $\sigma$ is the standard deviation of the error in the growth equation. It is clear from this expression that $E(\triangle y \mid x, s=1)$ is the sum of a linear function $x \beta$ and the nonlinear Inverse Mills ratio. The nonlinear form of the Inverse Mills ratio is based crucially on the normal-linear assumptions of the model and any deviations from it would affect how $E(\triangle y \mid x, s=1)$ changes as a consequence of marginal changes in $x$ making it a tenuous approach to addressing selection (Manski, $2007)^{7}$

\section{Data}

The data used for the analysis comes from the Oxford Firm Level IP database (OFLIP). The database draws on the Financial Analysis Made Easy (FAME) data that covers

\footnotetext{
${ }^{6}$ Otherwise variation in the Inverse Mills ratio is not independent from variation in $X_{i}$ preventing identification of $\beta$.

${ }^{7}$ Das et al. (2003) and Newey (2007) have proposed alternative, non-parametric estimators for correcting for selection. These methods have attractive characteristics that may make them well suited for analysis of patenting, but work in this direction is left for a future paper.
} 
the entire population of registered UK firms (FAME downloads data from Companies House records). ${ }^{8}$ OFLIP contains additional information on the IP activity of firms in the form of patents and trademarks. OFLIP has been constructed by matching the FAME database and a number of firm-level IP data sets. ${ }^{9}$

The FAME database is a commercial database provided by Bureau van Dijk. ${ }^{10}$ To construct the data set, the December 2006 edition of FAME has been used. The financial data was updated using the May 2008 edition of FAME. FAME covers around 2.04 million active firms. For all of these firms, basic information, such as name, registered address, firm type, and industry code are available. Availability of financial information varies substantially across firms. The smallest firms are legally required to submit only very basic balance sheet information such as shareholders' funds and total assets, which imposes severe constraints on the analysis of small firms. Importantly, the FAME database also lists around 0.9 million so called 'inactive' firms. These inactive firms are those that have exited the market and belong to one of the following categories: dissolved, liquidated, entered receivership or declared non-trading. Also, FAME gives exact dates for market entry in the form of a firm's incorporation date, which allows us to identify our cohort of firms set up in 2000. To determine date of exit we use the date that the last set of accounts were filed.

The intellectual property (IP) data used for the construction of OFLIP database comes from three different sources: the UK IP Office, Marquesa Ltd. and the European Patent Office (EPO) ESPACE Bulletin. Data on UK patent publications were supplied by the UK IP Office. Marquesa Ltd supplied data on UK trademark publications and Community (OHIM) marks registered. Data on EPO publications by British entities was downloaded from ESPACE Bulletin DVD 2006/001. The analysis uses the application date of UK and EPO patents, and trademarks. ${ }^{11}$ This said, only patents that are published are in the public domain. Hence, it is not possible to observe those patents that were withdrawn before their publication. Given the usual 18 months period between application and publication date, we should observe all patents that made it to the publication stage. Note that for this paper, we have complemented OFLIP

\footnotetext{
${ }^{8}$ In the remainder of this work we use firms to mean registered firms. Hence firm refers to the legal entity that organizes production, in contrast to census-type data that uses the plant or production unit.

${ }^{9}$ For details on the matching process and further details on the database see Rogers, Helmers, and Greenhalgh (2007).

${ }^{10}$ http://www.bvdep.com/en/FAME.html

${ }^{11} \mathrm{It}$ is possible that small UK firms file for patents at the US PTO, which we do not have data for; however, our view is that the numbers involved are likely to be low. We do have patents filed at WIPO under the PCT if they have subsequently been published in the UK or at the EPO.
} 
with patents and trademarks applied by firms' directors. FAME indicates the names and addresses of firms' directors, which enabled us to match them to the patent and trademark data sets. In summary, we create an indicator variable that takes the value of one if a firm applied for a patent either (a) itself in 2000 or 2001 or (b) through one of its directors in 1999, 2000, or 2001. ${ }^{12}$ Similarly, for trademarks, the indicator variable assumes the value of one if a firm applied for a trademark (a) itself in 2000 or 2001 or (b) through one of its directors in 2000 or 2001.

The objective is to analyze the effect of patenting on start-up firms, which should be regarded to an overwhelming extent as small firms, at least during their initial years of existence. To ensure this we only include firms with less than $£ 2.4$ million in total assets in its first set of accounts (the EU definition of a small firm). In our data, about $40 \%$ of firms fail during the 2000-2005 period and, of the surviving ones, only $3.21 \%$ grow from the micro category into the small and medium size (SME) category and $0.22 \%$ into the large firm category. ${ }^{13}$ The medium- and high-tech sectors in the sample are listed in Table $1 .^{14}$ The use of assets as our size and growth measure is due to reporting requirements in the UK. All firms must report assets to Companies House, whose data is in turn imported into FAME. Using turnover data would create a severe sample selection bias as only larger firms are required to report turnover.

The information on firms' exit decisions allows us to distinguish firms that do not report asset data from firms that have exited. This is a distinct advantage of our data. ${ }^{15}$ However, here is a potential problem since $13 \%$ of the firms in the sample do not report asset data either in 2001 or 2005, or both, despite the fact that they are still operating at the end of 2005. This represents a problem of missing data. Instead of omitting the observations for which we do not observe growth rates, we impute missing asset data to obtain full coverage of growth rates for the sample of surviving firms. Crucially, the ability to impute missing values and to obtain consistent estimators of any model using the data rests on the 'missing at random' assumption. In our case, because the only

\footnotetext{
${ }^{12}$ If a director applied for a patent in 1999, before officially assuming his post as a director of the start-up, this implies that the start-up was launched to market the patent application. This does, of course, assume that the director's patent is related to the start-up's activities. This may not be true if the director had other business or research interests, but we adjudge this to be unlikely in the majority of cases.

${ }^{13} \mathrm{~A}$ micro firm has total assets less that $£ 1.3$ million, an SME has assets less than $£ 28$ million, and a large firm above this. These are based on EU definitions.

${ }^{14}$ We employ the OECD definition of medium- and high-tech sectors adding the SIC-2003 sectors 722 and 731. Section 6 analyses whether restricting our sample to the OECD definition significantly affects our results.

${ }^{15}$ We have also attempted to discover which small firms were taken over in the period. However, the merger and acquisition databases provided by Bureau van Dijk and Thomson have very little data on small firms.
} 
Table 1: Industries in the Sample

\begin{tabular}{lc}
\hline \hline Description & SIC-3 \\
\hline Manufacture of Chemicals and Chemical Products & 24 \\
Manufacture of Machinery and Equipment & 29 \\
Manufacture of Office Machinery and Computers & 300 \\
Manufacture of Electrical Machinery and Apparatus & 31 \\
Manufacture of Radio, Television and Communication Equipment & 32 \\
Manufacture of Medical, Precision and Optical Instruments & 33 \\
Manufacture of Motor Vehicles, Trailers and Semi-Trailers & 34 \\
Manufacture of Railway and Tramway Locomotives & 352 \\
Manufacture of Aircraft and Spacecraft & 353 \\
Software Consultancy and Supply & 722 \\
R\&D on Natural Science and Engineering & 731 \\
\hline \hline
\end{tabular}

missing variable is the dependent variable, the 'missing at random' assumption is equivalent to the 'selection on observables' assumption, i.e., $P(m=1 \mid y, x)=P(m=1 \mid x)$, where $m$ is an indicator variable equal to one if the outcome variable is missing and zero otherwise. ${ }^{16}$

The sample contains 303 patentees. Of these, $83 \%$ survived to 2005 , which is much higher than the $60 \%$ for the entire sample. Of the 303 patentees, around $70 \%$ of them applied for a UK patent and $58 \%$ applied for a EPO patent $(28 \%$ of them applied for both UK and EPO patents). Firms' directors applied for $36 \mathrm{UK}$ patents, 47 EPO patents and $32 \mathrm{UK}$ trademarks.

\section{Descriptive Analysis}

In this section, we summarize the data through their unconditional distributions and relate these distributions to each other. Table 2 shows unconditional distributions of growth rates across firms. Growth rates are calculated as the difference between the log of a firm's total assets in 2005 and 2001 (divided by four to express annual growth). A feature of these tables is a 'hollowing-out' effect, i.e., that IP-active firms are more concentrated either in the low growth or the high growth quartile. Table 2 provides first strong evidence that the distributions of IP-active and IP-inactive firms differ. In order to verify this for the entire distributions, Figure 2 plots the unconditional probability density functions of growth rates of patenting against non-patenting firms. The

\footnotetext{
${ }^{16}$ Note that this is weaker an assumption than 'missing completely at random', which assumes that $m$ is independent of $(y, x)$.
} 
distribution of patenting firms appears to be characterized by a shape shift vis-à-vis the non-patenting firm growth distribution, while the location of the distributions appears similar. The analysis will investigate whether both distributions, summarized by their means, are statistically significantly different from each other. The important assumption made in such an analysis is that both distributions are comparable once we condition them on the set of variables $X_{i}$ in combination with our timing assumption and homogeneity of the sample analyzed.

Tables 3 and 4 provide summary statistics for the sample of surviving firms. Table 3 contains the entire sample of survivors used in the growth regressions, whereas Table 4 splits the sample into patenting and non-patenting firms. It provides additional evidence by showing summary statistics for patenting and non-patenting firms which applied for a trade mark. The university variable measures the minimum geographical distance from a firm's location to the nearest university. The variable is computed by matching firms' postcodes and universities' postcodes with Code-Point data provided by Edina Digimap. ${ }^{17}$ Given the grid points for firm $i$ and university $j$, bilateral geographical distances are calculated. ${ }^{18}$ The subsidiary variable is a binary variable indicating whether a firm is part of a holding company (FAME contains information on the ownership structure of firms). However, ownership data are only available for the last set of financial accounts of any firm (e.g. 2005 for survivors), hence the variable does not capture possible changes in a firm's status through time.

\section{Results}

The first table of results (Table 5) shows a set of OLS regressions for both the basic data and also the imputed data. The dependent variable is the annual average growth rate of assets over the period 2001 to 2005 . The variable patent is a dummy variable for whether the firm had a patent, either UK or EPO. The binary variables UK patent and EPO patent simply break this dummy variable into its two components. The results on all the patent variables are significant and positive, with the imputed sample showing higher values for patent and EPO patent. For reference, the $95 \%$ confidence interval for the 0.147 coefficient on patent in regression (1) is between 0.09 and 0.20 . The results also indicate that trade marking (in 2000 and 2001) is statistically significantly associated with subsequent asset growth. The number of directors also has a positive association with a firm's growth rate. In contrast, greater distance from a university and larger initial size have negative associations with firms' growth rates.

\footnotetext{
${ }^{17}$ http://digimap.edina.ac.uk/main/index.jsp

${ }^{18}$ Distance $=\sqrt{\mid \text { northing }_{i}-\text { northing }\left._{j}\right|^{2}+\mid \text { easting }_{i}-\text { easting }\left._{j}\right|^{2}}$.
} 
As discussed in Section 2, the OLS results may suffer from sample selection bias. Table 6 shows the standard Heckman model (using FIML) with the survival model results in the lower part of the table and the growth model results in the upper part of the table. The survival model also includes a number of industry and regional variables which are intended to capture entry and exit costs and the ability to refinance (see Appendix A). The survival model indicates that IP activity is positively associated with survival. Specifically, the coefficients on the patent dummies are all positive and significant, and their magnitudes imply substantial increases in survival probability. Moreover, a Lagrange Multiplier test for $\rho$, capturing correlation between unobservables affecting survival and unobservables affecting firm growth, being equal to zero is rejected at the $1 \%$ level for all four specifications (1) - (4). Hence, the estimates for $\rho$ indicate statistically significant negative correlation between unobservables suggesting the presence of selection bias in the OLS results.

The upper half of the table shows that the coefficient estimates on the patent dummy in the growth model are reduced by more than half. This suggests that failing to control for selection creates a substantial upward bias in the patent coefficient due to only using surviving firms. The results are broadly consistent whether we use the sample with or without the imputed values. The growth model results also show that the coefficients on the $U K$ or EPO dummy variables are always positive but only significant for the EPO dummy in regression (4).

The magnitude of the coefficient on the patent dummy in the growth models (1) and (3) in Table 6 is 0.06 and 0.08 respectively. This implies that when we control for selection bias, a patentee is associated with a $6 \%$ to $8 \%$ higher growth rate per annum. This is just below the $95 \%$ confidence interval from the OLS results in regression (1) reported in Table 5.

A further issue concerns whether any potential growth impact of patenting depends on the influence of firm size. One hypothesis might be that patenting can only benefit firms of a certain size since only these have the necessary resources to pursue and defend their intellectual property. Even though all the firms here are small, the initial size in 2001 still varies up to 2.4 million pounds. One way to investigate this is to create an interaction term between the patent dummy and asset size in 2001, and enter this as an additional explanatory variable (in both selection and growth model). Table 7 shows the coefficients for patent and interaction terms from a Heckman model (other coefficients are omitted since they are very similar to those reported in Table 6. As 
can be seen, the results indicate that the interaction term is negative but statistically insignificant in most cases. The exception to this is for the patent dummy in the nonimputed sample, and the results for EPO patents in both samples. The significant, negative coefficient on the interaction between EPO dummy and a firm's initial assets is consistent with smaller patentees having higher growth.

\section{Robustness}

As discussed earlier, constraining the sample to high- and medium-tech industries is important to limit heterogeneity. However, even within these industries there is variation across start-ups. To investigate the implication of this, industries 722 and 731 were dropped. Software Consultancy and Supply (722) has the most start-ups and some of these may be related to service-based ideas that have less inventive content; R\&D on National Science and Engineering (731) is a specialized classification and may, therefore, introduce undesired heterogeneity in firms' propensity to patent. Removing these two industries reduces the sample size for the non-imputed sample in the selection stage from 7,038 to 1,407 and in the growth regression from 3,981 to 1,000 . The results from reproducing Table 6 with the smaller sample confirm the general pattern of results discussed above. For the patent variables the coefficients are generally higher. In particular, the coefficient on the patent variable in Table 6 for the non-imputed sample was 0.08 , whereas in Table 8 , the coefficients is three times as large. Also the coefficients of the binary variables $U K$ patent and EPO patent in column (4) of Table 8 are both statistically significant and much larger in magnitude than the coefficients reported in column (4) of Table 6 .

\section{Conclusion}

This paper has used new data on the IP activity of all UK firms in an attempt to assess the impact of patenting on start-up firms. The paper analyzes the growth rate of assets (2001 to 2005) of medium- and high-tech start-ups incorporated in 2000. Growth of assets are used since this is the only measure of firm size that must be reported by small firms. Patenting is measured by a patent application in 1999 to 2001 (which was subsequently published). Importantly, we take account of the patenting activity of the firm's directors (in 1999 to 2001) to capture the fact that firms are often incorporated to exploit inventions of specific scientists or entrepreneurs. Trying to assess any impact of patenting on performance faces a range of difficulties. There is huge heterogeneity in start-up firms with many firms being unlikely to patent, hence our focus on mediumand high-tech start-ups. The paper assumes that all such start-ups have a new idea 
that could, in principle, be patented. Further, we assume that the decision to patent is made in 1999 to 2001, which is prior to full engagement in market activity. This reduces concerns over simultaneity (i.e., that high growth increases chance of patenting).

Any identification of the impact of patenting on firm performance relies on the assumption that all start-ups (in their first year of existence) have similar expectations regarding their future growth rate (i.e., it is not only high growth potential firms that patent). This assumption is based on two observations. First, entrepreneurs in medium- and high-tech industries tend to be optimistic and expect their projects to be highly successful. Second, patents are not viewed by entrepreneurs as the only method of exploiting good ideas.

The low survival rate of start-up firms means that it is particularly important to control for sample selection. The data set used here is rich enough to allow us to do this as it records the exit of any firm and we can distinguish this from simply missing values. Using a standard Heckman selection model we find that sample selection appears to be important. In estimating the selection model we also find that patenting has a strong positive association with survival. The Heckman model finds that the association between patenting and subsequent asset growth is between $6 \%$ and $8 \%$ (i.e., a start-up that patents in 1999-2001 has a $6 \%$ to $8 \%$ higher annual growth rate between 2001 and 2005 than a firm that does not patent). The $95 \%$ confidence intervals for these point estimates are between $0 \%$ and $12.3 \%$ and $2.2 \%$ and $13.7 \%$ respectively. There is also some evidence that this association is higher for smaller firms. As is well known, the Heckman model results are sensitive to the joint normality assumptions it relies on. The OLS results ignoring sample selection suggest a patent to be associated with between $9 \%$ and $20 \%$ higher subsequent annual growth.

The paper has not been able to investigate reasons why such an association might exist. Clearly, our assumptions regarding the timing and nature of the decision to patent are critical to any interpretation. Even if there is some underlying causality between patents and performance, it is not clear what might be driving this. Start-up firms could be using patents as a signal to capital markets, which then allows them to borrow more. Having more finance available could then allow higher growth (in fact, borrowing money to buy assets would have a direct impact on our asset growth measure). Alternatively, start-up firms might find having a patent(s) helps in negotiations with customers or suppliers. Finally, patents may have their traditional benefit of providing some degree of market power. 


\section{References}

[1] Arora, A., Ceccagnoli M. and W. M. Cohen (2008). 'R and D and the Patent Premium.' International Journal of Industrial Organization 26: 1153-1179.

[2] Astebro, T. (2003). 'The Return to Independent Invention: Evidence of Unrealistic Optimism, Risk Seeking or Skewness Loving?' Economic Journal 113(484): 226239.

[3] Buddelmeyer, H., P. Jensen and E. Webster (forthcoming). 'Innovation and the Determinants of Company Survival.' Oxford Economic Papers.

[4] Das M., Newey W. and F. Vella (2003). Nonparametric estimation of sample selection models, Review of Economic Studies, Vol. 70, pp 3358.

[5] Browning, M. and J.Carro (2006). 'Heterogeneity and Microeconometrics Modelling', CAM Working Papers 2006-03, Copenhagen: University of Copenhagen, Department of Economics, Centre for Applied Microeconometrics.

[6] Disney, R., Haskel, J. and Heden, Y. (2003). 'Entry, exit and establishment survival in UK manufacturing', Journal of Industrial Economics, Vol. 51(1), pp. 91-112.

[7] Gambardella, A., Harhoff D. and Verspagen B. (2008). 'The Value of European Patents'. CEPR Discussion Paper 6848.

[8] Gowers, A. (2006). 'The Gowers Review of Intellectual Propoerty. Report for the UK Treasury' http:www.hm-treasury.gov.uk.

[9] Heckman J. (1976). 'The Common Structure of Statistical Models of Truncation, Sample Selection and Limited Dependent Variables and a Simple Estimator for Such Models, Annals of Economic and Social Measurement, Vol. 5, pp. 475492.

[10] Heckman J. (1979). 'Sample Selection Bias as a Specification Error', Econometrica, Vol. 47, pp. 153161.

[11] Hicks, D. and Hegde D. (2005). 'Highly Innovative Small Firms in the Markets for Technology.' Research Policy 34(5): 703-716.

[12] Manski C. (2007). 'Identification for Prediction and Decision', Harvard University Press.

[13] Mata J. and Portugal P. (1994). 'Life Duration of New Firms', The Journal of Industrial Economics, Vol. 42, No. 3., pp. 227-245. 
[14] Newey W. (2007): Nonparametric continuous/discrete choice models, International Economic Review, Vol. 48(4), pp. 14291439.

[15] Rogers M., Helmers C. and Greenhalgh C. (2007). 'An analysis of the characteristics of small and medium enterprises that use intellectual property', Oxford Intellectual Property Research Centre.

[16] Rosenbaum P. and Rubin D. (1983). 'The Central Role of the Propensity Score in Observational Studies for Causal Effects', Biometrika, Vol. 70, No. 1, pp. 41-55.

[17] Schankerman, M. and Pakes A. (1986). 'Estimates of the Value of Patent Rights in European Countries During the Post-1950 Period.' Economic Journal 96: 10521076 . 


\section{A Appendix: Description of variables used in selection equation}

The survival indicator of the selection equation is constructed using the information of 'inactive' firms available in FAME. Inactive firms are those that have exited the market and belong to one of the following categories: dissolved, liquidated, entered receivership or declared non-trading. This information on inactive firms allows us to identify all firms entering and exiting the market throughout the five-year period analysed.

The minimum efficiency scale is calculated as the ratio of average first-year firm size to average firm size within the SIC-3 industry.

Capital intensity is computed as the ratio of the amount of firms' assets and labor within each SIC-3 industry.

The 4-firm concentration ratio is computed as the share in total assets of the four largest firms within a SIC-3 industry.

Unemployed rates are measured as the ratio of unemployed over all economically active persons by county and unitary authority. For Northern Ireland, we used the unemployment rate at the country level. The data for the UK comes from the UK Office for National Statistics' Labour Force Survey (LFS) where we calculated annual averages from the quarterly data available. 
Figure 2: Density Distributions of Patenting vs. Non-Patenting Firms

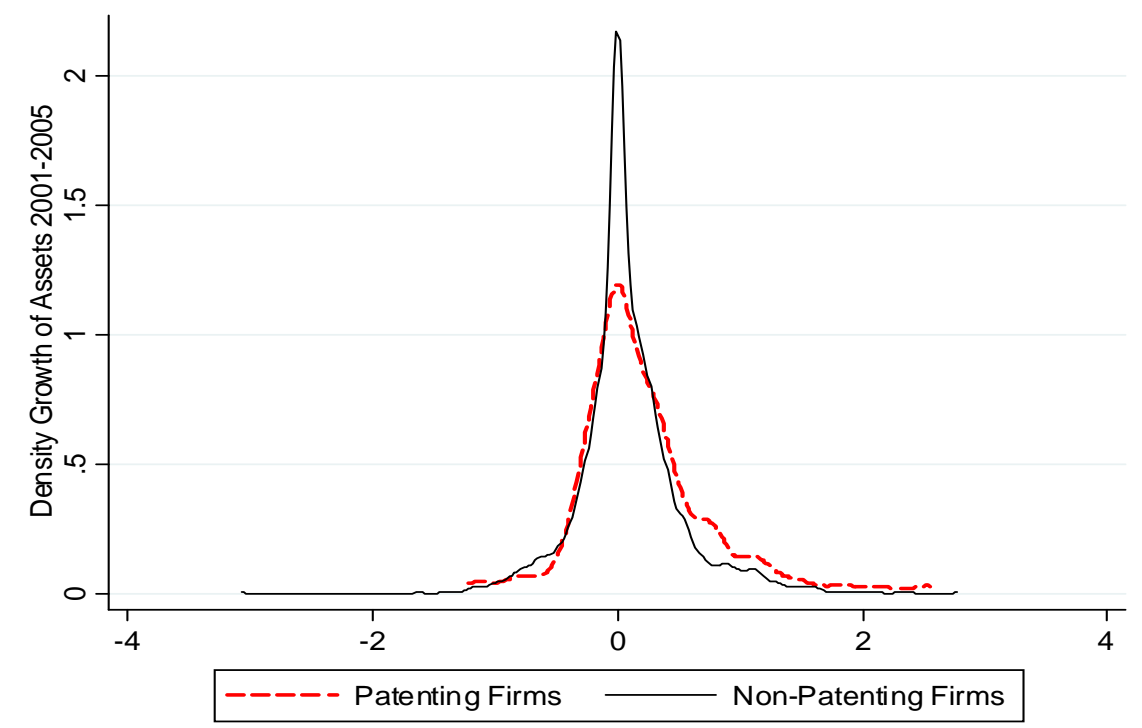




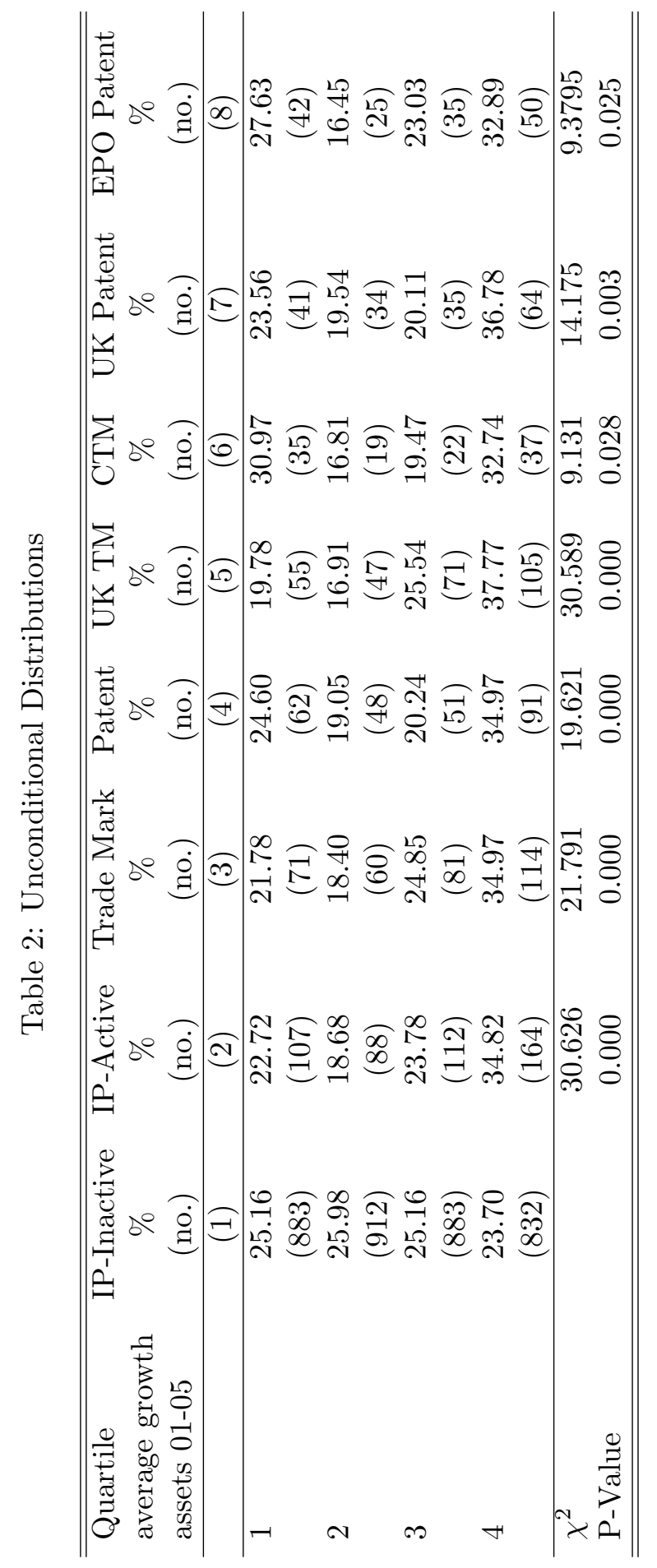


Table 3: Summary Statistics: Growth Regression

\begin{tabular}{lcccccc}
\hline \hline Variable & Mean & Median & $25 \%$ & $75 \%$ & St. Dev. & Observations \\
\hline Growth Assets 2001-2005 & 0.095 & 0.029 & -0.097 & 0.262 & 0.428 & $(6)$ \\
UK Patent & 0.044 & 0 & 0 & 0 & 0.204 & 3981 \\
EPO Patent & 0.038 & 0 & 0 & 0 & 0.192 & 3981 \\
Patent & 0.063 & 0 & 0 & 0 & 0.244 & 3981 \\
Trademark & 0.082 & 0 & 0 & 0 & 0.274 & 3981 \\
ln Dist. University & 1.768 & 1.871 & 0.986 & 2.501 & 0.909 & 3981 \\
ln Directors & 1.106 & 1.098 & 0.693 & 1.386 & 0.429 & 3981 \\
Subsidiary & 0.069 & 0 & 0 & 0 & 0.253 & 3981 \\
ln Assets in 2001 & 3.235 & 3.148 & 1.658 & 4.363 & 2.392 & 3981 \\
\hline \hline
\end{tabular}




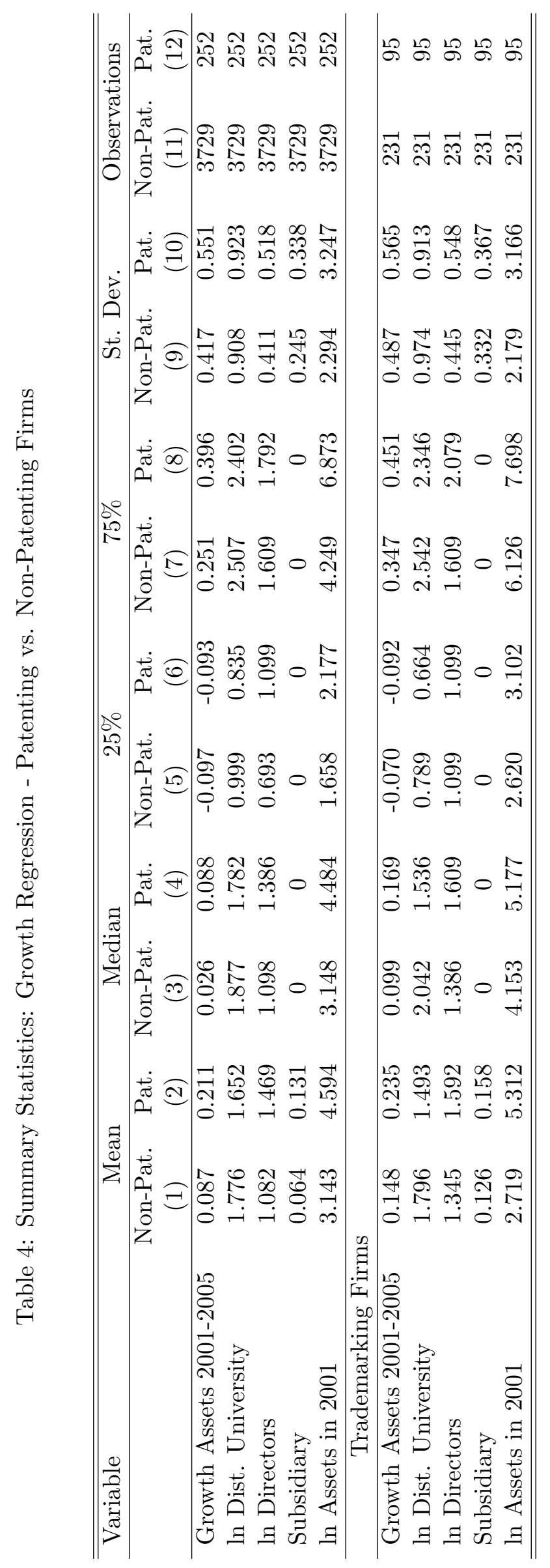


Table 5: Results: OLS

\begin{tabular}{lcccc}
\hline \hline Covariate & \multicolumn{4}{c}{ Asset Growth 2001-2005 } \\
& $(1)$ & $(2)$ & $(3)$ & $(4)$ \\
\hline & $0.147^{* *}$ & & $0.167^{* *}$ & \\
\hline Patent & $(0.033)$ & & $(0.026)$ & $0.106^{* *}$ \\
UK Patent & & $0.101^{*}$ & & $(0.033)$ \\
& & $(0.043)$ & & $0.143^{* *}$ \\
EPO Patent & & $0.119^{* *}$ & & $(0.036)$ \\
& & $(0.044)$ & & $0.120^{* *}$ \\
Trade Mark & $0.122^{* *}$ & $0.120^{* *}$ & $0.122^{* *}$ & $(0.023)$ \\
& $(0.028)$ & $(0.028)$ & $(0.023)$ & $0.131^{* *}$ \\
ln Directors & $0.110^{* *}$ & $0.109^{* *}$ & $0.133^{* *}$ & $(0.016)$ \\
& $(0.019)$ & $(0.019)$ & $(0.015)$ & $-0.018^{* *}$ \\
ln Dist. University & $-0.017^{*}$ & $-0.017^{*}$ & $-0.018^{* *}$ & $(0.007)$ \\
& $(0.007)$ & $(0.007)$ & $(0.006)$ & $-0.089^{* *}$ \\
ln Assets in 2001 & $-0.074^{* *}$ & $-0.075^{* *}$ & $-0.088^{* *}$ & $-0.003)$ \\
& $(0.004)$ & $(0.004)$ & $(0.003)$ & $(0.003)$ \\
Subsidiary & 0.027 & 0.026 & 0.002 & 0.001 \\
& $(0.034)$ & $(0.033)$ & $(0.024)$ & $(0.024)$ \\
\hline$R^{2}$ & 0.151 & 0.151 & 0.201 & 0.201 \\
No. Obs. & 3981 & 3981 & 4407 & 4407 \\
\hline \hline
\end{tabular}

Notes:

1. Robust Standard Errors in parentheses.

2. ${ }^{+}$indicates significance at $10 \% ;{ }^{*}$ at $5 \%$; ${ }^{* *}$ at $1 \%$. 
Table 6: Results: Heckman Selection Correction (ML Estimates)

\begin{tabular}{|c|c|c|c|c|}
\hline \multirow[t]{2}{*}{ Covariate } & \multicolumn{4}{|c|}{ Asset Growth 2001-2005 } \\
\hline & (1) & $(2)$ & $(3)$ & $(4)$ \\
\hline Patent & $\begin{array}{c}0.063^{*} \\
(0.030)\end{array}$ & & $\begin{array}{c}0.080^{* *} \\
(0.029)\end{array}$ & \\
\hline UK Patent & & $\begin{array}{c}0.048 \\
(0.037)\end{array}$ & & $\begin{array}{c}0.049 \\
(0.036)\end{array}$ \\
\hline EPO Patent & & $\begin{array}{c}0.062 \\
(0.040)\end{array}$ & & $\begin{array}{l}0.084^{*} \\
(0.039)\end{array}$ \\
\hline Trade Mark & $\begin{array}{c}0.056^{*} \\
(0.027)\end{array}$ & $\begin{array}{l}0.052^{*} \\
(0.027)\end{array}$ & $\begin{array}{l}0.055^{*} \\
(0.026)\end{array}$ & $\begin{array}{l}0.052^{*} \\
(0.026)\end{array}$ \\
\hline ln Directors & $\begin{array}{c}0.082^{* *} \\
(0.017)\end{array}$ & $\begin{array}{c}0.080^{* *} \\
(0.017)\end{array}$ & $\begin{array}{c}0.103^{* *} \\
(0.016)\end{array}$ & $\begin{array}{c}0.101^{* *} \\
(0.016)\end{array}$ \\
\hline ln Dist. University & $\begin{array}{c}-.025^{* *} \\
(0.007)\end{array}$ & $\begin{array}{c}-0.026^{* *} \\
(0.007)\end{array}$ & $\begin{array}{c}-0.026^{* *} \\
(0.007)\end{array}$ & $\begin{array}{c}-0.027^{* *} \\
(0.007)\end{array}$ \\
\hline ln Assets in 2001 & $\begin{array}{c}-0.076^{* *} \\
(0.003)\end{array}$ & $\begin{array}{c}-0.076^{* *} \\
(0.003)\end{array}$ & $\begin{array}{c}-0.090^{* *} \\
(0.003)\end{array}$ & $\begin{array}{c}-0.091^{* *} \\
(0.003)\end{array}$ \\
\hline Subsidiary & $\begin{array}{c}0.026 \\
(0.025)\end{array}$ & $\begin{array}{c}0.025 \\
(0.025)\end{array}$ & $\begin{array}{c}0.003 \\
(0.024)\end{array}$ & $\begin{array}{c}0.002 \\
(0.024)\end{array}$ \\
\hline No. Obs. & 3981 & 3981 & 4407 & 4407 \\
\hline Covariate & & Survi & $\begin{array}{r}\text { al } 2001-20 \\
\text { Imp }\end{array}$ & Values \\
\hline & (1) & $(2)$ & $(3)$ & $(4)$ \\
\hline Patent & $\begin{array}{c}0.918^{* *} \\
(0.120)\end{array}$ & & $\begin{array}{c}0.898^{* *} \\
(0.118)\end{array}$ & \\
\hline UK Patent & & $\begin{array}{c}0.631^{* *} \\
(0.147)\end{array}$ & & $\begin{array}{c}0.624^{* *} \\
(0.144)\end{array}$ \\
\hline EPO Patent & & $\begin{array}{c}0.815^{* *} \\
(0.172)\end{array}$ & & $\begin{array}{c}0.799^{* *} \\
(0.169)\end{array}$ \\
\hline Trade Mark & $\begin{array}{c}0.742^{* *} \\
(0.088)\end{array}$ & $\begin{array}{c}0.743^{* *} \\
(0.088)\end{array}$ & $\begin{array}{c}0.707^{* *} \\
(0.086)\end{array}$ & $\begin{array}{c}0.707^{* *} \\
(0.086)\end{array}$ \\
\hline ln Directors & $\begin{array}{c}0.211^{* *} \\
(0.039)\end{array}$ & $\begin{array}{c}0.211^{* *} \\
(0.040)\end{array}$ & $\begin{array}{c}0.217^{* *} \\
(0.039)\end{array}$ & $\begin{array}{c}0.218^{* *} \\
(0.039)\end{array}$ \\
\hline CR-4 & $\begin{array}{c}1.014^{* *} \\
(0.115)\end{array}$ & $\begin{array}{c}1.023^{* *} \\
(0.115)\end{array}$ & $\begin{array}{c}1.009 * * \\
(0.111)\end{array}$ & $\begin{array}{c}1.019 * * \\
(0.111)\end{array}$ \\
\hline MES & $\begin{array}{l}18.396^{+} \\
(10.080)\end{array}$ & $\begin{array}{l}18.374^{+} \\
(10.098)\end{array}$ & $\begin{array}{c}17.125^{+} \\
(9.928)\end{array}$ & $\begin{array}{c}17.111^{+} \\
(9.946)\end{array}$ \\
\hline Capital Intensity & $\begin{array}{c}0.0002^{* *} \\
(0.000)\end{array}$ & $\begin{array}{c}0.0002^{*} \\
(0.000)\end{array}$ & $\begin{array}{c}0.0002^{* *} \\
(0.000)\end{array}$ & $\begin{array}{c}0.0002^{* *} \\
(0.000)\end{array}$ \\
\hline Unemployment & $\begin{array}{c}-5.072^{* *} \\
(0.796)\end{array}$ & $\begin{array}{c}-5.042^{* *} \\
(0.795)\end{array}$ & $\begin{array}{c}-4.481^{* *} \\
(0.772)\end{array}$ & $\begin{array}{l}-4.458 \\
(0.770)\end{array}$ \\
\hline$\rho$ & $\begin{array}{l}-0.511 \\
(0.49)\end{array}$ & $\begin{array}{l}-0.515 \\
(0.478)\end{array}$ & $\begin{array}{l}-0.552 \\
(0.045)\end{array}$ & $\begin{array}{l}-0.557 \\
(0.044)\end{array}$ \\
\hline $\operatorname{LR}(\rho=0)$ & $\begin{array}{c}38.16 \\
\mathrm{p}=0.000\end{array}$ & $\begin{array}{c}40.36 \\
\mathrm{p}=0.000\end{array}$ & $\begin{array}{c}44.91 \\
\mathrm{p}=0.000\end{array}$ & $\begin{array}{c}47.75 \\
\mathrm{p}=0.000\end{array}$ \\
\hline No. Obs. & 7038 & 7038 & 7464 & 7464 \\
\hline
\end{tabular}


Table 7: Results for interactions: Heckman Selection Correction (ML Estimates)

\begin{tabular}{|c|c|c|c|c|}
\hline \multirow[t]{2}{*}{ Selected covariates } & \multicolumn{4}{|c|}{ Asset Growth 2001-2005 } \\
\hline & (1) & (2) & (3) & (4) \\
\hline Patent & $\begin{array}{c}0.124^{* *} \\
(0.048)\end{array}$ & & $\begin{array}{l}0.110^{*} \\
(0.046)\end{array}$ & \\
\hline Patent $\mathrm{x} \ln ($ asset $)$ & $\begin{array}{r}-0.014+ \\
(0.008)\end{array}$ & & $\begin{array}{l}-0.007 \\
(0.008)\end{array}$ & \\
\hline UK patent & & $\begin{array}{c}0.056 \\
(0.059)\end{array}$ & & $\begin{array}{c}0.045 \\
(0.057)\end{array}$ \\
\hline UK patent $\mathrm{x} \ln$ (asset) & & $\begin{array}{c}0.000 \\
(0.011)\end{array}$ & & $\begin{array}{c}0.002 \\
(0.011)\end{array}$ \\
\hline EPO patent & & $\begin{array}{c}0.195^{* *} \\
(0.070)\end{array}$ & & $\begin{array}{c}0.180^{* *} \\
(0.067)\end{array}$ \\
\hline EPO patent $\mathrm{x} \ln ($ asset $)$ & & $\begin{array}{c}-0.027^{*} \\
(0.012)\end{array}$ & & $\begin{array}{r}-0.020+ \\
(0.012)\end{array}$ \\
\hline No. Obs. & 3981 & 3981 & 4407 & 4407 \\
\hline
\end{tabular}


Table 8: Robustness Test Results (without SIC-3 722 and 731): OLS and Heckman Selection Correction (ML Estimates)

\begin{tabular}{|c|c|c|c|c|}
\hline \multirow[t]{2}{*}{ Covariate } & \multicolumn{4}{|c|}{ בAsset Growth 2001-2005 } \\
\hline & (1) & $(2)$ & $(3)$ & (4) \\
\hline \multirow{2}{*}{ Patent } & $0.154^{* *}$ & & $0.241^{* *}$ & \\
\hline & $(0.051)$ & & $(0.052)$ & \\
\hline \multirow[t]{2}{*}{ UK Patent } & & $0.117^{+}$ & & $0.175^{* *}$ \\
\hline & & $(0.063)$ & & $(0.064)$ \\
\hline \multirow[t]{2}{*}{ EPO Patent } & & 0.103 & & $0.165^{*}$ \\
\hline & & $(0.073)$ & & $(0.076)$ \\
\hline \multirow[t]{2}{*}{ Trade Mark } & $0.068^{+}$ & 0.065 & $0.141^{* *}$ & $0.137^{* *}$ \\
\hline & $(0.041)$ & $(0.041)$ & $(0.050)$ & $(0.041)$ \\
\hline \multirow{2}{*}{ ln Directors } & $0.083^{*}$ & $0.080^{+}$ & $0.109^{* *}$ & $0.105^{* *}$ \\
\hline & $(0.041)$ & $(0.042)$ & $(0.038)$ & $(0.038)$ \\
\hline \multirow[t]{2}{*}{ ln Dist. University } & -0.018 & -0.017 & -0.005 & -0.004 \\
\hline & $(0.015)$ & $(0.015)$ & $(0.015)$ & $(0.015)$ \\
\hline \multirow{2}{*}{ ln Assets in 2001} & $-0.069^{* *}$ & $-0.069^{* *}$ & $-0.060^{* *}$ & $-0.060^{* *}$ \\
\hline & $(0.006)$ & $(0.006)$ & $(0.005)$ & $(0.005)$ \\
\hline \multirow{2}{*}{ Subsidiary } & -0.042 & -0.045 & $-0.092^{*}$ & $-0.093^{*}$ \\
\hline & $(0.057)$ & $(0.057)$ & $(0.045)$ & $(0.045)$ \\
\hline$R^{2}$ & 0.188 & 0.188 & & \\
\hline No. Obs. & 1000 & 1000 & 1000 & 1000 \\
\hline \multirow[t]{2}{*}{ Covariate } & & & \multicolumn{2}{|c|}{ Survival 2001-2005 } \\
\hline & & & $(3)$ & $(4)$ \\
\hline \multirow[t]{2}{*}{ Patent } & & & $0.608^{* *}$ & \\
\hline & & & $(0.159)$ & \\
\hline \multirow[t]{2}{*}{ UK Patent } & & & & $0.371^{*}$ \\
\hline & & & & $(0.188)$ \\
\hline \multirow[t]{2}{*}{ EPO Patent } & & & & $0.585^{*}$ \\
\hline & & & & $(0.262)$ \\
\hline \multirow[t]{2}{*}{ Trade Mark } & & & $0.402^{* *}$ & $0.391^{* *}$ \\
\hline & & & $(0.142)$ & $(0.143)$ \\
\hline \multirow[t]{2}{*}{ ln Directors } & & & $0.241^{* *}$ & $0.227^{* *}$ \\
\hline & & & $(0.085)$ & $(0.086)$ \\
\hline \multirow[t]{2}{*}{ CR-4 } & & & 0.003 & 0.003 \\
\hline & & & $(0.194)$ & $(0.194)$ \\
\hline \multirow[t]{2}{*}{ MES } & & & 11.123 & 11.127 \\
\hline & & & $(8.887)$ & $(8.897)$ \\
\hline \multirow[t]{2}{*}{ Capital Intensity } & & & 0.000 & 0.000 \\
\hline & & & $(0.000)$ & $(0.000)$ \\
\hline \multirow[t]{2}{*}{ Unemployment } & & & $-3.804^{*}$ & $-3.771^{*}$ \\
\hline & & & $(1.575)$ & $(1.574)$ \\
\hline \multirow[t]{2}{*}{$\rho$} & & & 0.797 & 0.798 \\
\hline & & & $(0.034)$ & $(0.034)$ \\
\hline \multirow[t]{2}{*}{$\operatorname{LR}(\rho=0)$} & & & 25.76 & 25.59 \\
\hline & & & $\mathrm{p}=0.000$ & $\mathrm{p}=0.000$ \\
\hline No. Obs. & & & 1407 & 1407 \\
\hline
\end{tabular}

Notes:

1. Robust Standard Errors in parentheses in columns (1) and (2).

2 . ${ }^{+}$indicates significance at $10 \% ;{ }^{*}$ at $5 \% ;{ }^{* *}$ at $1 \%$. 